\title{
Küresel Çağ Tartışmaları Altında Milliyetçiliğe Yeniden Bakmak: Yeni Osmanlıcılık Söyleminin İnşas1
}

\author{
DOI: $10.26466 /$ opus.536362 \\ * \\ Dilan Çiftçi ${ }^{*}$ Fuat Boğaç Evren**
*Assist. Prof. Dr., Gazetecilik Bölümü, Yakın Doğu Üni., Yakın Doğu Bulvarı, Lefkoşa/Kıbrıs E-Posta: dilan.ciftci@neu.edu.tr ORCID: 0000-0003-3806-3915
E-Posta: fuat.evren@neu.edu.tr $\quad$ ORCID: $\underline{0000-0003-1325-3878}$ \\ ** Res. Assist., Görsel İletişim ve Tasarım Böl.Yakın Doğu Üni., Yakın Doğu Bul., Lefkoşa/Kıbrıs
}

\begin{abstract}
$\ddot{O} z$
Küreselleşme kavramının birbirinden oldukça farklı biçimlerde algılanmasl, ne zaman ortaya çıktı̆̆ına dair görüş ayrılıklarının yaşanması ve çağımızın en önemli siyasi tartışmaları arasında kendisine yer bulması, ilgili kavramın detaylı bir literatür taramasıyla ele alınmasını gerekli kılmıştır. Keza küreselleşme kavramının salt bir ekonomik ifade olduğunu varsaymak ya da sadece üretim ilişkileriyle değerlendirmek batı menşeli hâkim kültürü anlayabilmemizin ve onun alt metnini okuyabilmemizin önündeki en önemli engeldir. Bununla birlikte küreselleşme olgusunun milliyetçilikle olan ilişkisinin ele alınması, özellikle günümüzde hem Türkiye'de, hem de Avrupa'da ve ABD'de milliyetçiliğin artması nedeniyle önem taşımaktadır. Özellikle milliyetçi politikalarla küreselleşmeye yönelik devlet politikaları her ne kadar birbirine zit görünse de ortak noktaların saptamak, her iki politikanın birlikte yürütülmesi ve bunun sonuçları, bu makalenin konusudur. Çalışmada öncelikle, küreselleşmenin eleştirisi ortaya konmuştur. Bununla birlikte, çalışma bir ideoloji olarak ele aldığı milliyetçilik kavramını iletişimde önemli bir yer bulan söylem inşası üzerine yapılan çalışmalarla devam etmiştir. Çalışmada milliyetçi söylemin inşası üzerine yapılan çalışmalarda kültürel göstergeler de yerini bulmaktadır. Bu çalışma da hem küreselleşme, hem de milliyetçilik kavramları açıklanmaya çalışırken, her iki kavramın birbiriyle olan ilişkisi, milliyetçi söylem kavramıla birlikte ele alını, konuya ilişkin güncel ve önemli örneklerden biri olan 'Yeni Osmanlıcılık' söylemiyle incelenecektir. Bu bağlamda yapılan tartışmalar Türkiye'de son dönemde artan Osmanlı bağlantılı değişimler ve isimlendirmeler irdelenirken küreselleşme ile birlikte milliyetçilik ortaya konulacaktır.
\end{abstract}

Anahtar Kelimeler: Küreselleşme, milliyetçilik, milliyetçi söylem, Yeni Osmanlıcılık, milli kimlik 


\title{
Revisiting Nationalism Under Global Age Discussions: The Construction of the New Ottoman Discourse
}

\begin{abstract}
The concept of globalization has to be dealt with in a very different way. The differences of opinion about globalization emerged when it is placed among the most important political debates of our time. Likewise, assuming that the concept of globalization is a mere economic expression, or evaluating only with the relations of production is the most important obstacle to our understanding of the dominant culture of western origin and ability to read its subtext. Therefore, there is a necessity for a detailed literature review of the relevant concept. Addressing the relationship between nationalism and globalization is also urgent today, since not only in Turkey, but also in Europe and in the United States, we are witnessing the gradual increase in the nationalist ideologies. First, the critique of globalization has been put forward which the study continued with the studies on the construction of the discourse, which had an important place in the communication. In the study, cultural indicators are also found in the studies on the construction of nationalist discourse which has been accepted as a type of ideology. In particular, although nationalist policies and state policies for globalization seem to be opposed to each other, the common point of the two policies is to determine their common points, and the consequences thereof are the subject of this article. In this study, the concepts of globalization and nationalism are tried to be explained. In addition to this the relationship between the two concepts will be studied together with the concept of nationalist discourse and examined with the discourse of "new Ottomanism" which is the current and important examples of the subject. In this context of discussions on the recent changes in Turkey linked to rising Ottoman ties will be put in the evaluation when the study argues naming nationalism within the globalization perspective.
\end{abstract}

Keywords: Globalization, nationalism, nationalist discourse, new Ottomanism, national identity. 


\section{Giriş}

Küreselleşme kavramının etrafında yürütülen tartışmalar, onu tanımlama biçimleri, onun tüm dünyayı topyekûn olumlu anlamda değiştireceğine inanan yaklaşımlar ve onun baştan sona tehlikeli bir şey olarak algılanması, bize küreselleşmenin çağımızın en önemli siyasi tartışmaları arasında yer aldığını göstermektedir. Kavramın popülaritesinin yanı sıra onu anlama da ve yorumlama da yaşanan görüş ayrılıkları, şüphesiz ki kavrama ilişkin net bir tanımlamanın yapılamamasından kaynaklanmaktadır. Her ne kadar kaygan ve tanımlanması güç bir şey gibi görünse de, küreselleşmeyle ilgilenen bilginlerin ona dair tanımlamalarında ve yorumlarında görüş birliği sağladığı noktaların, sermayenin ucuz emek gücüne duyduğu ihtiyaç, ham maddeye yakın olma ve sermayenin pazarı geniş̧letme çabaları olduğu söylenebilir. ${ }^{1}$

20. yüzyıldan itibaren iletişim teknolojilerinde başlayan baş döndürücü değişimler ve gelişmeler, dünyanın giderek daha küçük ve daha birleşik bir biçimde algılanmasına yol açmıştır . Bu algıyı oluşturan neden; insanlar, toplumlar ve ülkeler arasındaki sınırlar üstü etkileşimin artması olmuştur. Böylelikle herhangi bir ülkede yaşanan ekonomik krizin, siyasi krizin, halk ayaklanmasının, askeri darbenin, demokratik atılımların ve hukuksal reform girişimlerinin diğer ülkeleri az ya da çok şiddetle etkilemesi olağanlaşmaya başlamıştır. Bu durum ülke sınırlarının "flulaşmasını" ya da başka bir deyimle 'sınırlar-üstü' yeni bir etkileşim biçiminin ortaya çıktığına da işaret etmektedir.

Kapitalist üretim tarzının doğasında genişleme ve yayılma dinamiği taşımasının bir sonucu olarak görebileceğimiz küreselleşmenin, siyasi, ekonomik ve kültürel birçok boyutu bulunmaktadır. Bu çalışmada da siyasi-kültürel boyutlarıla ve etkileriyle ele alınacak olan küreselleşmenin, doğası gereği ve özellikle onun "sınırlar-üstü" etkisine muhalif yaklaşması beklenen milliyetçilikle olan ilişkisi tartışılacaktır. Çünkü bu çalışma için milliyetçi ideolojiyi küreselleşmeyle açılamak yerine ya da onu küreselleşmenin bir sonucu olarak görmek yerine, onun, küreselleşmenin ülke sınırlarını 'flulaştırıcı' gücü karşısındaki tutumunu

\footnotetext{
${ }^{1}$ Özellikle sermayenin ucuz emek gücüne duyduğu ihtiyaca, günümüzün en büyük küresel sermayelerinden birisi olarak görülen Apple teknoloji şirketinin California'dan (ABD) yönetilmesine karşın, üretiminin büyük çoğunluğunu Çin'de gerçekleştirmesi örnek gösterilebilir.
} 
ve gösterdiği direnci -eğer gösteriyorsa- konu almak daha anlamlıdır. Bu nedenle, Türkiye ile birlikte Avrupa'da aşırı sağcı partilerin yükselişi küreselleşme olgusunun doruğa ulaştığı 21. yüzyılda milliyetçiliğin artış nedenlerini, küreselleşmeye karşı milliyetçi siyaset yapma biçimini ve milliyetçiliğin küreselleşmeyle entegrasyonunu tartışmayı gerekli kılmıştır.

Söz konusu tartışmayı yürütmeyi amaçlayan çalışmanın temel sorunsalı da küreselleşmenin etkilerini bu denli etkili ve derin gösterdiği bir çağda milliyetçiliğin nasıl yükseldiği üzerine kurulmuştur. Bununla birlikte milliyetçi ideolojinin küreselleşmeyle birlikte onun yarattığ olaylara ve olgulara karşı yaklaşımının sorgulanması da çalışmanın temel konularından birisidir. Tartışmanın temel dinamiklerini oluşturan millet ve milliyetçilik kavramlarına, küreselleşmenin temel toplumsal dinamikleri olan iletişim ağı, kentleşme, kapitalizm, neo-liberalizm ve çok ulusluluk gibi olgular çerçevesinde yaklaşılmasından farklı olarak, küreselleşmenin eleştirileriyle ve boyutlarıyla birlikte söylem kavramıla da yaklaşılacaktır. Bu anlamda öncelikle küreselleşmenin eleştirilerine ve boyutlarına, ardından da milliyetçi ideolojiye ve söylem tanımlamasından hareketle milliyetçiliğe yeniden bakmak için milliyetçi söylem kavramına ve tartışmalarına yer verilecektir.

On yılı aşkın süredir Türkiye'nin siyasal ve aynı zamanda toplumsal gündeminde hızla yükselen şekilde yer bulan Yeni Osmanlıcılık kavramı siyasal jargonda ve toplumsal dağarcıklarda yer etmeye başlamıştır. Bu hızlı yer bulmada gündelik yaşamın içersin de çeşitli biçimlerde siyasal alan terminolojinde yer bulmasında medyanın payı büyüktür. Kavram ihtişamlı bir geçmiş anlatısını imgelerken yeni siyasal kimlikler kurmanın da pratiklerini medya tarafından inşaa edilen hikayeler aracılığıyla sağlamaktadır. Bu anlatılar sosyal ve duygusal yatırımlar aracılığı ile dünyayı bilme, anlama ve anlamlandırmanın yapı taşlarını oluşturmaktadır. Tüm bu sebepler hasebiyle bu kavram üzerinden yürütülecek her araştırma başlı başına akademik bir merakın nesnesi olacak niteliktedir. $\mathrm{Bu}$ çalışmada sosyal bilimlerde kullanılan nitel araştırma desenlerinden durum çalışması yapılmıştır. Bu noktada küreselleşme eleştirisi birden fazla durum ele alınarak Türkiye' deki küreselleşme tartısmaları sınırları içerisinde bütüncül olarak analiz edilmiştir. Çalışmada çok boyutlu veri top- 
lama araçları kullanılmıştır. Toplanan verilen küreselleşme tartışmalarındaki milliyetçilik olgusu betimleme, örnekleme ve Türkiye'deki küreselleşme ve milliyetçilik temalarındaki Yeni Osmanlıcılık örüntülerini ortaya çıkarmak için söz konusu kavramları öncelikle tek başına daha sonra ise karşılaştırmalı olarak tanımlanmış ve yorumlanmıştır.

\section{Küreselleşme ve eleştirisi}

İlk kez Marshall McLuhan tarafından ortaya atılan "küresel köy" tanımlamasıyla "küresel" kavramının kullanımı ve onun etrafından kurulan tartışmalar, 1960'lardan günümüze dek yaygınlaşarak devam etmiştir (Karyelioğlu, 2008, s.125-126). 1980'lerden itibaren küreselleşme kavramına olan ilginin artmasına karşın, terim hâlen, bir süreci, bir siyaseti, bir pazarlama stratejisini ve hatta bir ideolojiyi anlatmak üzere kullanılmaktadır. Burada küreselleşmeyle ilgili problem, onun tek bir süreç olmayıp birbiriyle çakışan, iç içe geçen, kimi zaman da çelişen ve karşıt olan bir süreçler kompleksi olmasıdır. Bu nedenle küreselleşmeyi tek bir sürece ya da meseleye indirgemek yanıltıcıdır (Heywood, 2014, s.189).Küreselleşmeyi modernizmin devamı şeklinde, kapitalizmin doğal gelişim sürecinin vardığ 1 son nokta olarak veya tarihteki küreselleşme biçimlerinin sonuncusu olarak değerlendirerek onu coğrafi keşiflerle başlatmak ya da günümüzün sosyo-ekonomik bileşenlerinin geçmişten farklılığına dayanarak "yeni bir durum" şeklinde görmek mümkündür (Karyelioğlu, 2008, s.125127).Küreselleşmenin ortaya çıkışıyla ilgili Keşifler Çağı, İngiltere'de Sanayi Devrimi'nin başlangıcı, sanayileşme hareketinin Avrupa'ya yayılması ile Avrupa, Amerika ve kısmen Uzak Doğu arasında bağlantıların başlaması, küreselleşmenin ortaya çıkışına ilişkin önemli süreçler ve nedenler olarak görülmektedir. Ancak küreselleşme ağırlıklı olarak ekonomik bir olguysa ve tüm dünyanın tek bir pazar hâline dönüşüp, üretimin tek bir pazar için gerçekleştirildiğini ifade ediyorsa onu kapitalizmin ortaya çıkışından daha geriye götürmek mümkündür (Türkbağ, 2002,s. 280).Sürekliliği göz önünde bulundurulduğunda küreselleşme, ortaya ç1kışından itibaren küresel ölçekte yayılma potansiyeli taşıyan kapitalizmin bir sonucu olarak kabul edilse de onu kapitalizmin başlangıcıyla ya da daha öncesiyle başlatmak, kavramın kullanımını anlamsız kılacağı gibi 
aynı zamanda kapitalist dünyanın oluşum sürecinde meydana gelen olayları tek bir nedene dayandırması, indirgemecilik olarak görülebilir (Karyelioğlu, 2008, s.128-129).

Bununla beraber küreselleşmeye ilişkin en önemli görüş ayrılıkları, onun karşıtlığı ve taraftarlığ üzerine yaşanmaktadır. Öyle ki günümüzde bazı açılardan bu görüş ayrılığı, kapitalizm ve sosyalizm arasındaki ideolojik çatışma üzerine temellenen daha geleneksel sol-sağ ayrışmalarının yerini almıştır. Bunun nedeni olarak küreselleşmenin belirgin bir neo-liberal ideolojik karaktere sahip olması gösterilebilir. Küreselleşme taraftarları, genellikle kapitalizmin ekonomik refah yaratma ve yeni firsatlar sunma eğiliminde olduğunu, bundan daha fazla ülkedeki daha fazla insanın yararlanabileceğini savunmaktadır. Diğer yandan küreselleşme karşıtları da sömürüyle ilişkilendirilen büyük sermayelerin ucuz emek gücüne sahip olması ve küresel tek bir kültürü hâkim kılmaya çalışması nedeniyle küresel kapitalizmin yeni yoksulluklarla yeni adaletsizlikler yaratıp bütün insanları tek tipleştireceğini ileri sürmektedir (Heywood, 2014, s.192-193).Kazananlar, değişmez bir şekilde çok uluslu şirketler ve endüstriyel açıdan ileri olan ülkeler olurken, kaybedenler ise ücretlerin düşük olduğu, regülasyonun çok az olduğu, üretimin ülkelerin ve bireylerin ihtiyaçlarından çok küresel pazarlara endeksli olduğu bir dünyanın bireyleridir. Immanuel Wallerstein'nın vurguladığı eşitsiz siyasal ve ekonomik gelişmenin yapısal koşulu, ekonomik dünya sisteminin merkez ve çevre bölgeleri arasında gittikçe artan bir eşitsizliğe yol açmaktadır (Heywood, 2014, s.193-194).

Küreselleşme taraftarlarından Francis Fukuyama'nın ileri sürdüğü şey, küreselleşmenin ülkelerin demokratikleşmesi anlamında büyük katkılar sağlayacağ1 yönündedir. Bu görüş, küreselleşmeyle birlikte piyasa kapitalizminin genişlemesinin, liberal demokratik ilkelerin ve yapıların evrensel olarak kabulüne zemin hazırlayacağını da ifade etmektedir. Piyasa tarafından serbest bırakılan çeşitli baskılar, açık ve demokratik toplumlarda kontrol edilebileceğinden söz konusu ekonomik özgürlük kaçınılmaz olarak siyasal özgürlüğü de doğurmaktadır (Heywood, 2014, s.195). Diğer yandan küreselleşmenin ekonomik gücü -dolayısıyla siyasal gücü de-çok uluslu şirketlerin elinde toplaması, onun demokrasiyi zayıflatacağı görüşüne işaret eder. Bu şirketlerden sadece birisi olan General Motor'un bir yıllık geliri, neredeyse İrlanda, Yeni Zelanda, Uruguay, Sri Lanka, Kenya, 
Namibya, Nikaragua ve Çad'ın toplam milli hasılasına eşittir (Klein, 2011'den aktaran Heywood, 2014, s.195). Çok uluslu şirketlerin farklı ülkelere yatırım yapma istekleri onlara ucuz iş gücü, düşük maliyetli üretim, yeni sermaye piyasası ve demokratik kontrollerden kaçış gibi ayrıcaliklar sunması nedeniyle her zaman canlı kalacaktır (Heywood, 2014, s.195).

Peter Berger (2003), küreselleşmenin temel belirtileri olarak dört farklı yüzü olduğuna dikkat çekmektedir. Berger (2003), küreselleşmenin öncelikle ekonomik temelli sürecinde kültürel yüzü olduğuna değinerek onun bu yüzünü "Davos Kültürü" (elit kültür) şeklinde tanımlamıştır. Adını her yil Davos'ta toplanan Dünya Ekonomi Zirvesi'nden alan Davos kültürünün ana lokomotifi olan uluslararası ticaret, aynı zamanda ekonomik ve teknolojik küreselleşmenin de lokomotifi konumundadır. Vakıflar, sivil toplum örgütleri, akademiler ve çok uluslu örgütler gibi oluşumların unsurlarını oluşturduğu küreselleşmeyi de "faculty club culture" olarak adlandırmıştır. Küreselleşmenin, Berger'in "McWorld Culture" olarak isimlendirdiği bir diğer yüzü de Amerikan üniversitelerinin isimlerini, logolarını, armalarını ve sloganlarını taşıyan kıyafetler giymek, Amerikan dizi-filmlerini, sinema filmlerini izlemek ve Amerikan fast-foodlarını tüketmek gibi "Amerikan" damgalı popüler kültürü ifade etmektedir. Özellikle kent insanının yaşam biçimi haline gelen bu popüler kültür, aynı zamanda küresel kapitalizmin yeni gücünün göstergesidir."Evanjelik protestanlık" olarak adlandırılan küreselleşmenin son yüzü ise çoğulculuk, pazar ekonomisi ve demokrasi yanlısı bir söylemi Latin Amerika başta olmak üzere, Güney Pasifik, Güney Afrika, Doğu Avrupa ve Orta Doğu ülkelerine empoze etmektedir (Keyman ve Sarıbay, 2000, s.10).

Jan AartScholte (2005), küreselleşmenin insanlar arasındaki 'sınırlarüstü' etkileşimi arttırdığına dikkat çekerek, bu etkileşimin sınırları aşan bir karaktere sahip olması nedeniyle sınırların daha az öneme sahip olduğu bir sosyal alanı yeniden şekillendirmesine vurgu yapmaktadır. Buna verilebilecek örneklerden birisi elektronik paranın internet aracillğıyla ülkeler arasında çok kısa sürede transfer edilebilmesidir. Andrew Heywood'a göre mevcut durumla birlikte küreselleşme, çok kültürlülükle ve yerelleşmeyle de hareket etmektedir. Bu birliktelik, ulusalcılık ve milliyetçilik temelinde yükselen bağlılıkları azaltırken, onların yerine dini ve 
etnik (yerel) kimliklere olan bağlılığı artırmaktadır. Heywood bunun nedeni olarak, homojenleşme korkusunun veya tehdidinin bir emperyalizm şekli olarak algılanmasıyla kültürel ve siyasal direnişin ön plana çıkacağını göstermektedir. Ancak bu durum, yaklaşan veya yaşanan emperyalizm tehdidine karşı inşa edilecek milli kimlik aracılığıyla milli duyguların toplum nezdinde yükselmesine de neden olabilir. Bununla birlikte Heywood, tek bir küresel kültürün ortaya çıkmasının yanı sıra, hem gelişmiş hem de gelişmekte olan ülkelerde daha kompleks sosyal ve kültürel çeşitlilik kalıplarının da ortaya çıtığına işaret etmektedir. Çünkü Batılı ülkelerdeki insanlar, Coca-Cola, McDonald's, Nike gibi küresel markalar yerine gittikçe artan bir şekilde Batılı olmayan markalardan, ürünlerden, kültürlerden, sanat alanlarından ve dinlerden etkilenmektedir (Heywood, 2014, s.189-190).

Küreselleşmenin ekonomik boyutunun yaygın biçimde tartışılmasıyla birlikte salt ekonomik boyutu, dünya ölçeğinde kurulmuş hegemonyanın sürekliliği için yeterli değildir. Burada Batı'nın kendisini 'küresel özne' olarak meşrulaştırma çabası içinde olduğu ve bu küresel öznenin en çokta ortak tüketim kalıplarıyla belirlendiği söylenebilir. Kitle iletişim araçlarının yaygınlaştırdığı popüler kültür ve bitmek bilmeyen tüketim ihtiyacı, her şeyin bir tüketim nesnesi ve pazar ürünü haline dönüştürüldüğü dünyamızda salt tüketime dayanan bir kültür yaratmaktadır (Karyelioğlu, 2008, s.133-134). Böylelikle söz konusu tüketime dayanan kültür, 'küresel homojenleştirici' işlevi görmektedir. John Fiske (1996), bu tüketim ihtiyac1 durumunu karnaval hazlar olarak tanımlarken, "saldırgan bedenler" kavramsallaştırmasıyla bireyin kendini ifade edişinin altını çizer. Kültürel homojenlik ulusal anlamları ve değerleri tehdit ederek dünya insanları arasindaki kültürel sembolleri yüceltirken, ulusal kültürlerde de yeni değişimlere zemin hazırlamaktadır. Kültürel alandaki bu değişim, toplumlardaki tüketimin sosyal işlevinin benzer olmasını sağlarken ayn zamanda kimliğin temel kaynağı ve bireyin kendisini ifade etme işlevini de görmektedir (Yetim, 2002, s.134).

Sonuç olarak küreselleşme kavramını açıklamak ve anlamak için onu bir otomobilin üretim aşamalarına benzetebiliriz. Günümüzde hemen her otomobil üreticisi, bir otomobili tek bir fabrikada üretmiyor. Her bir parça ayrı ülkelerde üretiliyor ve yine ayrı bir ülkede montajı yapılarak satışa hazır hale getiriliyor. Çok uluslu şirketlerin üretim aşamalarında böyle bir 
tercihte bulunmasının nedeninde ucuz emek gücü yer almaktadır. Bu durum emeğin ve sermayenin parçalanması olarak görülmektedir. Ayrıca çok uluslu şirketlerin küresel nitelik taşıması, ulus devletlerin milli ekonomiyi geliştirme ve yerli üretimi artırma politikalarını tehdit etmektedir. Bununla birlikte yukarıda değinildiği üzere, herhangi bir ülkede yaşanan ekonomik kriz, siyasi kriz, halk ayaklanması, askeri darbe, iç çatışma ve savaş gibi ulus devletlerin varlığını tehlikeye sokacak olayların da küreselleşerek dünyanın bütün ülkelerini etkileyebilme dinamiğini taşımasının, ulus devletin mayası olarak görülen milliyetçi ideolojiyi nasıl etkilediğini, onun bu tür durumlar karşısında toplumun bütünlük ve ulus devletin varlığı açısından ne tür reaksiyonlar gösterdiğini açıklayabilmek için milliyetçilik ideolojisini ve onun yarattığı milli kimlik söylemini ele almak önem taşımaktadır.

\section{Bir ideoloji olarak milliyetçilik}

Özgün kullanımıyla millet, hiçbir siyasi atıf taşımamakla birlikte bir insan türünü ya da bir irksal grubutemsil etmektedir. Bireylerin salt bir ulus içinde yaşayarak gerçek özgürlüğe ve mutluluğa erişebilecekleri esasına dayanan milliyetçilik kavramı ise ilk kez Jakobenlere karşıt olan Fransız papazı AugustinBarruel tarafından kullanılmıştır (Smith, 2001, s.5758).Bir fikir olarak milliyetçilik, Fransız Devrimi'yle ortaya çıktı ve Fransız halkı, Jean-Jacques Rousseau'nun yazılarıyla "halkın kendi kendini yönetimi" fikrinden etkilendi (Heywood, 2013, s.161). Ayrıca milliyetçilik, tahtın tebaası yerine Fransa'nın vatandaşları olması gerektiği fikrini yansıtan devrimci bir inançtı².

Milliyetçiliğin bir yandan ulusal bağımsızlık vaat eden ilerlemeci ve özgürleştirici bir güç olarak görünmesi, diğer yandan siyasi liderlerin savaş siyaseti gütmelerine imkân sağlayan itici bir güç olması, onun tek veya

\footnotetext{
2 Burada şunu da eklemek gerekir; Fransız Devrimi bir halk devrimi değildi. Devrim öncesinde Fransa, Avusturya-Macaristan'a karşı girdiği savaştan mağlup ayrılınca devlet, ekonomik anlamda ciddi bir kriz yaşamış ve zaten yoksul olan halktan vergi alınamayınca da burjuvadan vergi almaya çalışmıştır. Buna karşılık burjuvazinin halkı krala karşı kışkırtması, 14 Temmuz 1789'da sonuçlarıyla siyasi anlamda tüm dünyayı etkileyen devrimi tetiklemiştir. Bu devrimin en önemli sonuçlarından birisi olan milliyetçilik, siyasi bir ideoloji olarak 19. yüzyılın başlarında Latin Amerika'ya sıçramış ardından etkilerini çok uluslu devletler olan Osmanlı, Avusturya-Macaristan ve Rusya'da da göstermiştir. Ayrıca devrimin yarattığı bir diğer önemli etki ise Insan Hakları Evrensel Bildirgesi'ne fikirsel anlamda ışı tutması olmuştur.
} 
tutarlı bir siyasi olgu olarak görülmesini zorlaştırmaktadır. Milliyetçiliğin bu iki gücünün yanı sıra kendinden olmayanı düşman görerek yabancı düşmanlığına, aşırı ırkçı fikirlere, çeşitli toplumsal grupları ötekileştirmeye ve yeni toplumsal sınıflandırmalara yol açacak zehirli bir yanının da olduğunu görmemezlikten gelemeyiz. Milliyetçiliğin bu denli farklı reaksiyonlar göstermesinin nedeni, şüphesiz ki liberallerin, muhafazakârların, sosyalistlerin, faşistlerin ve hatta komünistlerin de ilgi odağ 1 haline gelmesi ve benimsemesidir. Bu anlamda milliyetçilik kapsayı $\mathrm{c}$ bir ideoloji olarak görünse de, onun belli başlı görünümlerini şu şekilde sınıflandırmak mümkündür: Liberal milliyetçilik, muhafazakâr milliyetçilik, yayılmacı (sömürgeci-emperyalist) milliyetçilik ve anti-kolonyal(sömürgecilik karşıtı) milliyetçilik (Heywood, 2014, s.156).

Fransız Devrimi'ne kadar uzanan ve devrimin tüm değerlerini taşıyan liberal milliyetçilik, milliyetçiliğin en eski görünümüdür. 19. yüzyılın ortalarında Avrupalı devrimcilerin çoğunluğu için liberalizmle milliyetçilik ayrılmaz bir bütün olarak görülmüştür. Başlangıça birey, millet ve uluslararası siyasete ilişkin gelişmiş olan milliyetçi inançlar, büyük ölçüde liberal fikirlerin uygulamalarıyla şekillenmiştir. Liberalizmin temel dayanağı bireysel özgürlük savunusu üzerine kurulurken, liberal milliyetçilik iki açıdan özgürleştirici güce sahiptir. Birincisi, hem çok uluslu imparatorluklar hem de sömürgeci güçler tarafından uygulanan her türlü hâkimiyet ve baskıya karşıdır. İkincisi ise özyönetim ideali, liberal milliyetçiliğin temel dayanağını oluşturur. Liberal milliyetçiler temelde, milletlerin tıpkı bireyler gibi eşit olduğunu ve bu eşitliğin kendi kendini yönetme anlamında mutlak bir hak olduğunu savunur. Liberal milliyetçiliğin asıl hedefi salt bir milletin bağımsızlı̆̆ını ya da birleşmesini sağlamak değil, aynı zamanda dünyanın bağımsız devletlerini inşa etmektir (Heywood, 2013, s.174).

Muhafazakâr milliyetçilik, 19. yüzyılın başlarında düzene ve siyasi istikrara karşı tehdit oluşturan radikal bir güç olarak algılanırken, modern dönemde pek çok muhafazakâr için milliyetçilik bir inanç meselesi haline gelmiştir. Muhafazakâr milliyetçilik genellikle kurulu ulus devletlerde daha fazla gelişme göstermektedir. Muhafazakârlar, evrensel milliyetçilikten çok milli vatanseverlik kavramı üzerine yoğunlaşırken, bireylerin salt milli topluluk içinde anlam ve emniyet arayan sınırlı ve kusurlu var- 
lıklar olduğuna inanır. Asıl hedefleri, özellikle sosyalistler tarafından sahiplenen ve bölücü bir fikir olarak algıladıkları sınıf dayanışmasından toplumu uzaklaştırıp, yurtsever sadakatiyle milli birliği korumaktır. Ülke ve millet tarihinin parlak günlerine atıflarda bulunarak geriye dönük bir politika izlemeleri, tarihi günlerin ve askeri zaferlerin şaşalı ritüellerle anılmasına neden olmaktadır. Muhafazakâr milliyetçilik, özellikle milli kimliğin tehdit altında olduğu ya da yok olma riskiyle karşılaştığı dönemlerde daha fazla önem kazanır. Çünkü bu tür milliyetçiliğe göre başarılı ve istikrarlı toplumlar, salt milli değerlere ve ortak kültüre sahip olmak zorundadır. Ayrıca muhafazakâr milliyetçilere göre, farklı dinlere, mezheplere ve geleneklere sahip olan yabancıların ülkeye göçü kısıtlanmalı ve azınlıktaki etnik gruplar milli kimlik aracılığıyla asimile edilerek olası bölücü ve ayrılıkçı tehditler en aza indirilmelidir (Heywood, 2013, s.177178).

Yayılmacı milliyetçilik, 19. yüzyılın sonlarında özellikle Avrupalı devletlerin Afrika kapışmasına başlamasıyla ortaya çıkmıştır. İngiltere'de saldırganlığı, yayılmacılığı ve sömürgeciliği esas alan bu tarz milliyetçilik aşırı milliyetçilik kavramının kullanılmasına yol açmıştır. Yayılmacı milliyetçiliği, liberal milliyetçilikten ayıran en önemli fark, onun üstünlük ve baskı inancından doğan şovenist karakteridir³ ${ }^{3}$. Burada milletlerin özyönetim hakkı konusunda eşit olmadıkları ve bazı milletlerin diğerlerine karşı kaçınılmaz üstünlüklerinin olması inancı, şovenizmin temel dayanağını oluşturmaktadır. Şovenizm gibi pek çok diğer kavram tartı̧̧malarında olduğu üzere Edward Said (2013), bu durumu oryantalist bakış açısı altında oluşturulan "yeniden çizilen sınırlar, yeniden tanımlanan meseleler ve dünyevileşen din ve milliyetçilik" olarak ortaya koyar. Bununla birlikte, yayılmacı milliyetçilik aracılığıyla 19. yüzyılda Avrupalı ve Amerikalı beyaz halkların, Afrikalı ve Asyalı "siyah, sarı, kahverengi" halklardan entelektüel açıdan tartışılamaz derecede üstün oldukları inancı yaygın biçimde kabul görmüştür. Öyle ki Avrupalılar, sömürgeciliği ahlaki ve dini bir misyon şeklinde üstlenerek özellikle Hristiyanlığın güzelliklerini ve faydalarını, dünyanın geri kalan şanssız ve cahil halklarına ulaştırmak gibi ulvi bir amaca hizmet etmekteydi (Heywood, 2013,179).

\footnotetext{
${ }^{3}$ Şovenizm terimi, kendini fanatik bir biçimde Napoleon'a adayan Fransız asker Nicolas Chauvin'den türemiştir.
} 
Anti-kolonyal milliyetçilik, Avrupa'da doğan milliyetçilik fikrinin, sömürülen halklarda millet olma duygusunun oluşmasını ve Asya ile Afrika halkları arasında milli özgürlük arzusunun ortaya çıkmasını ifade etmektedir. Sömürgecilik karşıtı hareketlerin artmasıyla Avrupalılar kendi silahları olan milliyetçilik doktrinin kurbanı olmuştur. Asyalı ve Afrikalı sömürgecilik karşıtı siyasi liderlerin büyük çoğunluğu ise Batı karşıtlığı nedeniyle sosyalizmin farklı şekillerine ilgi duymaya başladı. Hindistan'da Gandhi ve Nehru 1lımlı ve barışçl bir sosyalizm algısını benimserken, Çin'de Mao Zedong, Vietman'da Ho Chi Minh, Küba'da Fidel Castro devrimci ve radikal bir Marksist politikanın uygulayıcısı oldu. Sömürgecilik sonrası dönem farklı milliyetçilik türlerini ortaya çıkarmakla birlikte söz konusu milliyetçilik tarzı, Batı'dan bağımsız kalmaktan ziyade tüm Batılı kültürlerin ve fikirlerin reddiyle şekillenmiştir (Heywood, 2013, s.181-183).

Yukarıda bahsedilen milliyetçilik türlerine bakıldığında, en azından liberal milliyetçiliğin, küreselleşme fikrine diğerlerine nazaran daha az karşı olabileceği söylenebilir. Milliyetçi ideolojinin bir ürünü olan ulus devlet biçimi ise daha eski siyasi yapılar karşısında üstünlüğünü kanıtlamıştır. Günümüzde de Çin'in en eski ve en son imparatorluğunun dönüşümüne tanıklık etmekteyiz. Georg Wilhelm Friedrich Hegel'e göre (2006) tarihsel bir yapı olgunluğa eriştiğinde yok olmaya mahkûmdur. Elbette ulus devletlerin modern öncesi siyasi yapıya karşı elde ettiği zaferi Hegel'in tarih felsefesiyle görmek zorunda değiliz. Ancak iletişimin küreselleşmesi, ekonomik üretimin ve parasal kaynakların küreselleşmesi, özellikle de ekolojik ve askeri risklerin küresel boyutlara ulaşması, tek başına ulus devletin ya da egemen devletlerin bir araya gelerek çözemeyeceği sorunlar olarak görülmektedir. Jürgen Habermas'a göre (2012, s.14-15)ulus devlet egemenliğinde yaratılan bu boşluk giderek artacak ve siyasi açıdan uluslar üstü bir seviyede yeniden yapılanmayı ve kurumsallaşmayı gerekli kılacaktır ki, Avrupa Birliği, Nato ve Birleşmiş Milletler de bunun örnekleridir.

Anthony D. Smith'e göre (2002), milliyetçi ideolojinin oluşumunda ve yaygınlaşmasında itici güçler olan ekonomik ve siyasal gelişmeler -yani, modernleşme süreçleri-, günümüzde bu ideolojinin önemini kaybetmesinde önemli rol oynamaktadır. Smith'in bu görüşünün temelinde etnik 
cemaatlerin ve milletlerin doğasına ilişkin çeşitli varsayımlar yer almaktadır. Bunlardan birincisi, milletler ve milliyetçilik kavramları modern olgular olarak kabul edilmektedir. İkincisi, söz konusu kavramlar, kapitalizmin, endüstriyelleşmenin, bürokrasinin, kitle iletişiminin ve sekülarizmin özgül modern koşullarının ürünleri olarak görülmektedir. Üçüncüsü, modernliğin gereksinimlerini ve onun toplumda yarattığı bütünlük-beraberlik ihtiyacını karşılamak üzere tasarlanan milliyetçilik, esas itibariyle yakın tarihin bir yapısı olan milletlerin temel dayanağıdır. Sonuncusu da her ne kadar oldukça eski ve yaygın olsa da etnik cemaatler, temelde iktidar mücadelesi içindeki elitlerin ve liderlerin kaynağ 1 ve aracı konumundadır. Bu görüşlerin temelinde ise modernliğin, kendisinden önceki dönemleri sonlandıran, onlarla birlikte daha önceki uzun çağlarda ortaya çıkan bütün yapıları ve inançları yok eden bir devrim niteliğinde olmasına dair temel varsayımlar yer almaktadır (Smith, 2002, s.26-27).

15. yüzyıldan itibaren Avrupa'daki geleneksel toplum yapısını sonlandırmaya başlayan modernleşme süreçleri, tarıma dayalı yaşamdan kent yaşamına, kapalı ekonomiden ülke ekonomisine ve homojenlikten uzak sinıf esaslı topluluk görünümünden güçlü milli bütünlüğe doğru yaşanan bir değişimi içerisinde barındırmaktadır (Oppenheimer,1997,s.138140).Marshall Berman'a göre (2013, s.28) modern hayat girdabının temelindeki; fiziksel bilimlerde gerçekleşen büyük keşifler, yeni tekelci iktidar ve sınıf mücadelesi biçimlerini yaratan endüstrileşme, hızlı ve çoğu kez sarsıntılı etkileri olan kentleşme, birbirinden çok farklı insanları ve toplumları birbirlerine bağlayan kitle iletişim sistemleriyle küresel kapitalist bir dünya pazarının oluşması, geleneksel toplum yapısının temel özelliklerinden birisi olan toplumsal bütünlüğü bozup, bu parçalanmışlık ortamında yeni bir bütünleşme ihtiyacını ortaya çıarmıştır. Yani, yerel ve geleneksel ortamlarından kopan bireylerin farklı ve kalabalık yeni mekânlarda yepyeni bir yaşam mücadelesine girmesi, kentleşmenin de etkisiyle bütünleştirici değerlerin azalmaya başlaması toplumsal anlamda bir krize yol açmıştır (Hekimoğlu, 1989, s.136). Bununla birlikte çeşitli nedenlerle o güne kadar siyaset dişında kalmış toplumsal kesimlerin siyasi katılım talepleri karşısında mevcut siyasi kurumların yetersiz kalışıla toplumsal eşitsizliğin daha da artarak devam etmesi, siyasal sistemde önemli bir meşruiyet boşluğu oluşmuştur. 
Milliyetçilik üzerine önemli tartışmalar yürüten Eric Hobsbawm'a göre (1993, akt. Yıldırım, 2015) gerek millet, gerekse milliyetçilik bir toplumsal mühendislik ürünüdür. Tarihsel analizlerinde özellikle gelenekler ve geleneklerin icat edilmesi üzerine duran Hobsbawm, 'icat edilmiş geleneklerin' en somut ve en yaygın örneğinin milli kimlikte ve milliyetçilikte görüldüğünü savunmaktadır. Aynı zamanda milliyetçiliğin, modern toplumsal dönüşüm süreçlerinde, modern yaşam biçiminin ve ona zemin oluşturan sanayileşmenin yol açtığı bölünmeler ve çözülmeler karşısında toplumsal bütünlüğü sağlamada can simidi görevini üstlendiğini de belirtmektedir (Hobsbawm, 1993, akt. Yıldırım, 2015, s.10-11).Aynı doğrultuda Benedict Anderson da, Hobsbawm'a benzer biçimde milletlerin ve milliyetçiliğin özel bir kültürel yapım ürünü olduğunu savunmaktadır. Anderson'a göre (2007, akt. Yıldırım, 2015) millet hem sınırlı, hem de egemen olacak şekilde hayal edilmiş bir topluluktur. Anderson'ı, Hobsbawm'un modern millet kavramsallaştırmasından ayıran fark, hayal edilmişliği sahte ve uydurma olarak görmemesidir. Ona göre doğal olan bu süreçte yüz yüze etkileşim kuramayan tüm topluluklar birbirini hayal etmek zorundadır. Bu nedenle milliyetçiliği kültürel alanlarda yaşanan modern süreçlerde arayan Anderson (2007, akt. Yıldırım, 2015, s.11), modern dönemle birlikte eski siyasi yapının bütünleştirici gücünü kaybetmesine karşılık ulus devleti hayal edilebilir topluluğa duyulan bir ihtiyaca dayandırmıştır.

Milliyetçi ideolojide siyasal egemenliğin sahibi ve kaynağ ulus olup, siyasal sistemin meşruiyet zeminini de ulusun kendisi oluşturmaktadır. Bölünmez bir bütün olarak görülen egemenlik ise ulusun sahibi ve kaynağı olduğu en yüksek otoritedir (Pierson, 2000, s.113'den aktaran Şahin, 2007, s.6).Bunun yanı sıra ulus, egemenliğin tek sahibi ve kaynağı olduğu için bir ülkede tek bir ulus ve tek bir milli kimlik olmalıdır. Söz konusu egemenlik gücünü elinde barındıran siyasi yapıda ülkenin tartışılmaz tek otoritesini temsil etmektedir (İzzet, 1969'dan aktaran Şahin, 2007, s.6).Milliyetçi politikaların önemli unsurlarından birisi de diğer kimliklerin temelini oluşturan ve onların en üstünde yer alan bir milli kimlik yaratmaktır. Çünkü milliyetçilik, ülkedeki bütün etnik, coğrafi, ekonomik ve tarihsel kaynaklı bölgeleşmeleri ortadan kaldırma ve onları homojenleştirme amacı güder. Bu amaç doğrultusunda "tek millet" in kültürel değerleri yüceltilerek tüm topluma ve ülkeye bu tek olan kültürü ortak-milli kimlik 
olarak göstermek ve kabul ettirmek milliyetçi ideolojinin temel reaksiyonudur (Şahin, 2007, s.6).

Modernistler için hem milletleri hem de milliyetçilikleri, modernliğin kendine has unsurları ve modern devletin yükselişinin kaçınılmaz bileşenleri olarak görmek gerekir. Bu yaklaşıma göre milletler ve milliyetçilik, önce erken dönem modern Batı' da, ardından Latin Amerika'nın, Asya'nın ve Afrika'nın sömürgecilik aracılığıyla işgal edilmiş topraklarında ortaya çıkmış teritoryal ve profesyonelleşmiş modern devletin yükselişinden ve doğasından türemiştir. Ayrıca milletler ve milliyetçilik, Avrupa'da yaşanan reformasyonun ardından devletle halk arasında açılmış olan boşluk için ve modernleşme süreçlerinin bireylerde yarattı̆̆ 1 yabancılaşma için köprü görevi görmektedir. Böylece milliyetçilik, modern toplumların çatışmalarını ve bölünmelerini dayanışmaya yönelik duygusal çağrılarla maskelemeye çalışmaktadır (Smith, 2002, s.34-35).

Sonuç olarak yaratılan ve yeniden üretilen milli kimliğe, milliyetçi duygularla üstü örtülmüş bir doğallık hissi verilir. Bu noktada, Smith'e göre, "modern millet miti" ortaya çıar ve bu mitin toplumda karşıllk bulacağı gerçeklik algısı da söylemler üzerinden inşa edilir (Yıldırım, 2015, s.15). Onun için, milliyetçi söylemin küreselleşme fikrine ve hareketine karşı ürettiği argümanları da ele almak açısından önem taşımaktadır. Burada milliyetçi söylemin küreselleşmesinden bahsederken dilbilimci Roland Barthes (1990),modern millet mitinin ideolojiden bağımsız düşünülemeyeceğini vurgularken, günlük hayatımızda bu mitlere maruz kalma durumumuzu da yine gelişen iletişim teknolojilerinin getirisi olarak görür. Bu bağlamda Barthes'a göre(1990) modern millet miti yerine "medya mitleri" kavramlarını kullanmak daha anlamlı olacaktır. Çünkü Barthes, mitlerin kültürde yerleşmiş olan hâkim değerlerin kültürel yeniden üretimi olduğunu ve anlaşılmasında ise ideolojinin anahtar konumda olduğunun altını çizer. Benzer şekilde John Fiske de(1996) mitlerin bir kültürün gerçekliğini ortaya koyduğunu ve geçmişe dönerek yeniden üretildiğini savunur. 


\section{Milliyetçi söylem}

Craig J. Calhoun'a göre (1997, s.22) farklı milliyetçilik biçimlerinin ortak noktalarını milliyetçi söylem dışında tek bir sürece -devlet inşası, modernleşme, ekonomik gelişmedeki eşitsizlikler gibi- bağlayarak açıklamak mümkün değildir. Söylem kavramının milliyetçilik ve kimlik çalışmalarında etkili bir konuma erişmesi de Michel Foucault'nun çalışmalarıyla gerçekleşmiştir. Temelde modern öznenin birey olarak kurgulanması üzerinde duran Foucault, çalışmalarında, "özne, nasıl formel bilginin bir problemi haline dönüştü?" ve "nasıl modernite öncesinin bireyi modernitenin toplumsal özneleri haline dönüştürüldü?" sorularına yanıt aramıştır (Yıldırım, 2015, s.16).Modern devleti, "bireylere rağmen, onların kim olduğuna aldırmadan, hatta varlıklarını bile yok sayan bir kendilik değil; tam tersine bu bireyselliğe yeni bir biçim tayin etmeleri ve belirli bir düzenekler toplamına tabi tutmaları koşuluyla, bireylerin onunla bütünleşebildikleri gelişkin bir yapı olarak düşünmek gerekliliği ortaya çıkıyor. Bir anlamda, devlet bir bireycilik ekseni veya yeni bir kırsal/çobanıl iktidar biçimi olarak görülebilir" şeklinde yorumlarken, milli kimliği modern bireyin bedenine işlenmiş görmektedir (Foucault, 1998, akt. Yıldırım, 2015, s.19-20).Söz konusu iktidar biçiminin toplumsaldaki kurgulanma biçimi de söylemsel alandan geçmektedir. Toplumsalda üretilen etkinlikler bütünü aynı zamanda anlamların ve simgelerin de üretilmesine katkıda bulunur. Milliyetçi söylem de bu anlamlar ve simgeler bütününün üretilmesini doğrudan etkilemektedir (Yıldırım, 2015, s.20).Toplumsal olan milliyetçi söylemin üretim aşamasında Ferdinand Saussure'ün dil kuramına değinmek bu noktada faydalı olacaktır. Şöyle ki, Saussure'a göre (2013) kimlik ve aidiyet belli başlı anlamları ve simgeleri kullanılarak ama daima dil pratikleriyle gerçekleşir. Burada milliyetçi söylem de tahmin edileceği üzere milliyetçi anlamları ve simgeleri kullanarak dil pratiklerini küresel düzende ortaya koyar.

Egemen bir temsil alanı olan milliyetçilik, savunduğu değerler gereği millete ilişkin karmaşıklığı ve olumsuzluğu reddeder. Ayrıca millet içindeki farklılıkların reddedilmesine de ihtiyaç duyar. Bu anlamdaki sembolik güçleri de milletin doğal bir kültürel ve siyasi birlik olarak tanımlanmasinda kendisine yer bulur (Brookes, 1999, s.248). Nitekim Habermas (2001), modern demokrasilerde milliyetçiliğin, siyasal iktidarlar ve siyasal 
liderler için halkı ülke sorunlarından ve çekişmelerinden uzaklaştırma da ucuz bir kaynak olduğunu ifade etmektir. Etienne Copeauxda (2002) Habermas'la aynı görüşü paylaşarak milliyetçiliğin doğallaştırıldığına ve insanlar tarafından bir ideolojiden ziyade, doğal bir erdemi ifade ediyormuş gibi algılandığına dikkat çekmektedir. Ayrıca Valentin Nikolaevich Volosinov, bu durumu millete özgü maddi kültürlerin toplamı olarak gördüğü için milliyetçi söylemin altını çizer. Gösterge üretimi, toplumsal formasyonların içerisinde ideolojiden beslenerek gerçekleşir ve ideolojinin işlendiği temel ortam dil ve bilinç pratiğidir (Voloshinov,1973). Daha da önemlisi hangi milliyetçi söylem ve ideoloji olursa olsun Voloshinov'a göre anlam dil yoluyla üretilir ve göstergeler anlamın maddi kayıtlarıdır. Buna ek olarak Louis Althusser'den yola çıarak anlamın toplumsal bir pratik olduğunu ve milliyetçi söylemde de görüldüğü üzere dil ve sembolleştirme anlamın üretildiği araçlar olduğu yargısına varılabilir (Althusser, 2010).

Milliyetçiliğin duygusal bir güç olması ve bireylere kendilerinden üstün bir varlıkla özdeşleşmelerini sağlayan gücü vermesi, farklılıklarına rağmen insanları birlikte tutan bir dayanışma kaynağı olarak görülmesiyle doğrudan ilişkilidir. Milliyetçilik, modernizmin yıkıcı dinamizmi içinde toplumlarda oluşan bütünlük ihtiyacını karşılamaya yönelik önemli bir işlevi görse de, sadece bir yanılsama ya da manipülasyon olsaydı bu gücüne sahip olamazdı (Calhoun, 1997, s.126). Milli kimliğin birbiriyle ilişkili olan etnik, kültürel, ekonomik ve siyasal birçok unsurdan meydana gelen karmaşık bir yapı olması, onun toplumsal varlığı oluşturan diğer kimlikleri dışladığı ya da onlardan üstün olduğunu göstermez. Çünkü milli kimlik ve onun içerdiği unsurlar, zaman içerisinde değişime uğrayabilmektedir (Hobsbawm, 1993, s.26). Saussure'un (2013) dil kuramında üzerinde durduğu şekliyle söylem ve göstergeler değişken olabilmektedir. Bu durumda milliyetçi söylemin zamanın içerisindeki değişimi ve yeni oluşan hali "art-süremli" söylemler olarak açıklanabilir. Burada dikkat edilmesi gereken nokta, milliyetçi söylemlerin aksine milletin bütün mensuplarını hepsi birmiş gibi ele aldığ Her birey milli kimliğini istediği şekilde konumlandırır. Tam olarak bu nedenle milli kimliğin kısa vadede dahi fikirsel anlamda değişimler yaşadığı söylemek mümkündür. 
Milliyetçiliğin hegemonik bir güç olabilmesi için gerçek anlamda milleti temsil etmesi gerekir. Onun için milliyetçilik, millet belirsizliğine belirli ve önemli ölçüde bütünsellik sağlayan bir mit olarak görülebilir. Bu nedenle milliyetçilik, "örnek millet" ve "örnek insanlar" yaratma eğilimindedir. Milliyetçi mit, hayal edilmiş belirli bir milli uzam adına toplumsal ve siyasal eylemin yol göstericisi olmayı amaçlar. Milli uzamın homojenleştirilmesi, millinin ne olduğuyla ilişkilidir. Ancak milleti belirleyen yapılar ne olursa olsun yine de bir şeyler eksik kalacaktır. Milletin homojenleştirilmesi ve ona gerçek bir varlık kazandırılması, milletin içindeki ve dışındaki "milli düşmanlar"ın söylemsel inşasıyla gerçekleşir (Torfing, 1999, akt. Gökalp, 2007, s.290).Bu noktada milletin, diğer milletlerden farklı ve ayrıcalıklı olduğu imajı yaratılır. Böylelikle diğer milletler de "yabancılar" veya "potansiyel düşmanlar" olarak görülerek zenofobi yaygınlaştırılır (Bech, 1999, s.118-119). Yabancılar her zaman kamusal tehdit unsuru olup ülke içinde ve dışında varlığını sürdürmektedir. Milliyetçilik için düşman imgeleri yaratmak, başta sınıf çatışması olmak üzere toplumdaki kültürel, etnik, cinsiyet gibi çatışmaları gizleyerek iktidarı kuvvetlendirir. Düşman imgeleri aynı zamanda, ulus devletlerin uyguladığı her türlü şiddeti bir karşı şiddet olarak meşrulaştırma aracı olup, bu imgeler aracılığıyla demokrasi dışı ve demokrasi karşıtı her türlü rıza kaynakları yaratılabilir (Beck, 1999, s.128-129).

Günümüzdeki ulus devletlerin büyük çoğunluğu birçok etnik grubu sınırları içinde barındırmakla birlikte bunu yaparken de diğer etnileri yok sayarak egemen bir etniyi temsil etmektedir ${ }^{4}$ İzlanda, Portekiz ve Norveç'in dişında hemen hemen bütün ulus devletler etnik olarak heterojen bir yapıya sahiptir. Ancak ulus devletin bütün yurttaşlarının tek bir etnik kültürü paylaşıyor olması dikkate alındığında, bugün mevcut devletlerin çok azının ulus devlet olduğu söylenebilir (Smith, 1994, s.33-35). Ulusla etniyi birbirinden ayıran en önemli şey, etninin bir ülkeye sahip olma iddiasının sembolik bir anlamı varken, ulusun bu talebi gerçek ve fizikidir. Ayrıca Smith (1994, s.41), etniyi tanımlarken önemli olanın ortak soy miti olduğuna dikkat çekerek etnisitenin ortak köken mitine dayandığını belirtmektedir.

${ }^{4}$ Etni: Etnik topluluk. 
Bir millete ya da ulus devlete ilişkin simgeler, egemen etninin imgelerini taşımaktadır. Bazı etnilerin kendilerini diğerlerinden üstün olarak tanımlamaları, milliyetçilik için olağanlaşmış bir durumdur. Çünkü etnilerin bir kimlik göstergesi ve köklerini arayış çabası olarak algılandığı çağrışımların aksine etnisizm, diğer etnik gruplara ilişkin geliştirilen bütünüyle olumsuz bir kavramsallaştırmadır (Fenton, 2001, akt. Gökalp, 2007, s.289). Sömürgeci ülkelerin, sömürülen halklara karşı uyguladığı milliyetçi söylemler bütününün Hindistan özelinde analizini yapan Partha Chatterjee, ithal edilen Avrupa merkezci bakış açısına dikkat çekmektedir. Chatterjee'ya göre (1996) milliyetçi söylem sorunu, sömürgeci bir egemenlik olarak işlemekle birlikte burjuva-rasyonalist kavramsallaştırılması sorununun özel bir görünümüdür. Bu doğrultuda Chatterjee, söylemin kendisinin evrensel bir ideal olarak egemenliğini ilan etmek için "öteki"ye ihtiyaç duyduğunu savunmaktadır. Genel olarak tüm kimlik formlarında olduğu gibi milli kimliklerde ötekilik sorunuyla, yani biz ve ötekiler ilişkisinin ürünüyle var olur (Chatterjee, 1996, akt. Yıldırım, 2015, s.21-22).Bu noktada Chatterjee'nın da belirttiği üzere, "milli biz"in oluşabilmesi için mutlaka ötekiye ihtiyaç vardır. Bununla birlikte diğer kimliklerde olduğu gibi, milli kimliğin ötekiye karşı tarifi ve inşası bir kereye mahsus olmayıp, sürekli olarak yeniden üretilmektedir (Gökalp, 2007, s.293). Bu noktada Enzo Traverso'nun belirttiği üzere (2009) toplumsal bellek tarihsel olanı yeniden çağırmada ve Maurice Halbwachs'un üzerinde durduğu şekliyle yeniden inşasında önemli rol oynar (Halbwachs, 1992). Ayrıca Henri Bergson'a göre(2015) yeniden üretim, geleneksel anlamların yeniden ve daimi sunumuyla güçlenir. Örnek vermek gerekirse bayrak, marş ve anıtlar gibi belli başlı maddi göstergeler bu sunumda önemli rol oynar. Bu maddi göstergelerin toplamı ise milliyetçi söylemi pekiştiren yapı taşları olarak anlam üretiminde kritik bir yere sahiptir.

Son olarak, milli kimliğin kurgulanması ve yeniden üretilmesi kadar aynı zamanda kolektif hafızayı oluşturmada söylemin yaratılması büyük öneme sahiptir. Çünkü her ulusun bir kolektif hafızasının olması gerekir. Bu doğrultuda milletin şanlı geçmişi ve zaferleri kutlanırken diğer yandan kolektif bir unutmada söz konusudur. Sürekli hatırlanıyormuş gibi görünse de unutulan sadece geçmiş değildir, sürekli olarak şimdiyi unut- 
mada söz konusudur. Bu bilinçle milli kimliği durmadan canlı tutan hatırlatmalar yapılarak, millet tarihinin zaferlerle dolu günleri gündelik toplumsal yaşamda bilindik kılınmaktadır (Billig, 2002).

\section{Küreselleşme fikrine karşı milliyetçiliğin tutumu}

Habermas'ın değindiği üzere (2001), artan küresel sorunlar karşısında ulus devletlerin, egemenlik haklarını özellikle 20. yüzyılın son çeyreğinden itibaren daha çok paylaşmak ve yeni bölgesel ya da küresel organizasyonlara devretmek zorunda kalması, küreselleşme, ulus-devlet ve milliyetçilik ilişkisine yeniden bakmayı gerekli kılmıştır. Esat Öz'e göre (2002, s.755) bu konuyu tartışan çalışmaların önemli bir kısmı, milliyetçilik karşıtı tarihi ve ideolojik ön yargılarla beslenerek ulus devlet ve milliyet kavramlarını hedef almıştır. Söz konusu saldırıların ortak noktasın da ulus devletlerin ömrünü büyük ölçüde tamamladığı iddiası yatmaktadır. Bu nedenle ulus devlet yapısı tasfiye edilerek bütün alt kimliklerle bireyselliğe yeni ve güçlü alanlar açacak demokrasiyi yeniden inşa etmek, evrensel bir gereklilik haline gelmiştir.

Ekonomiyle iletişim teknolojilerinin birbiriyle eklemlenmesi, yeni bir küresel kültürün yaygınlaşmasını hızlandırmakta ve milli kültür evrenlerine yönelik sürekli benzer davranışları ve tüketim modellerini aktarmaktadır (Mattelart, 2001, akt. Öz, 2002, s.757). Bu noktada Öz, milli kültürün ve milli kimliğin, yabancı-hâkim kültürün dalgalarına karşı dalga kıran işlevi gördüğünden bahsederek söz konusu kültüre ve kimliğe, ulus devleti ve onun mensuplarını yabancı kültür tehdidine karşı koruyan kalkan görevini yüklemektedir. Ayrıca milliyetçilik dışında, birey, piyasa ve sınıf merkezli bir dünya ve toplum için böylesi bir siyasi sorumluluk sistemini yaratacak başka bir ideoloji bulunmamaktadır (Öz, 2002, s.757-758). Öz'ün de değindiği üzere milliyetçiliğin, milletleri sürekli olarak tehdit eden küreselleşme karşısındaki tavır alma ve önlem biçimleri, genel olarak milliyetçiliği savunan görüşün tezini oluşturması anlamında önemlidir.

Küreselleşmenin ulus devletlerdeki toplumsal bağları zayıflatması bir yandan küresel bir kimliğin oluşmasına zemin hazırlarken, diğer yandan etnik kimliklerin önem kazanmasına neden olmaktadır. 'Toplumların McDonalds'laşması' gibi küresel kimlik oluşumların milli kimliği tehdit etmesine rağmen etnik kimliklerin gün yüzüne çıkması ulus devletler için 
daha büyük bir sorun olarak algılanmaktadır (Şimşek ve Ilgaz, 2007, s.195). Ayrıca etnik kimlikler desteklenerek milli kimliğin zayıflatılmasıyla birlikte bütün toplumların küresel güçlerin pazarı haline geleceğine yönelik bir inançta söz konusudur. Bu inanca göre ulus devletler yıkılarak onların yerin güçsüz, sömürüye açık ve asimile edilmeye müsait topluluklar oluşturacaktır (Şimşek ve Ilgaz, 2007, s.195-196). Küreselleşmenin, ulus devlet merkezli yaklaşımları zayıflattığını savunan David Held de (1995, s.138-139) aynı konuya dikkat çekmekle birlikte, uluslararası örgütlerin gücünü artırarak ulus devletler üzerinde yaptırım uygulayabilmesini ve buna paralel olarak ulus devletlerin siyaset alanını sınırladığını dile getirmektedir.

Küreselleşme süreçlerinin hem ulus devlet, hem de milliyetçilik açısından taşıdığ 1 tehdit unsurlarının ardından, gerek benzerleriyle karşılaştırıldığında güncelliğini koruması, gerekse geniş kitleler tarafından büyük yankı bulması nedeniyle, kimilerinin dış politikasında Türk milliyetçiliğinin ve muhafazakârlığının küreselleşme biçimi olarak algıladığı "Yeni Osmanlıcılık" fikrinin yarattı̆̆ı söylemlere ayrıca değinmek gerekmektedir. Milliyetçi ideolojinin yarattığı bir söylem olan Yeni Osmanlıcılıkla ilgili öncelikle eski bir imparatorluğunun gücüne duyulan hayranlığı taşıması nedeniyle ulus devletin varlığına aykırı olup, kendisini tehdit ettiğinden bahsetmeliyiz. Bu bağlamda medya toplumsal belleği canlı tutan bir aracı olmakla kalmayıp yeniden inşasında başkahramandır. Eski imparatorluğa duyulan hayranlık yeniden inşa edilirken yeni iletişim araçları eskinin temsili olacak şekilde ürünler ortaya koymaktadır. Tokdoğan (2018) 'Yeni Osmanlıcilığ, toplumsal tabanın arzularını, hırslarını, ofkelerini açı̆a çıkarıp, dönüștürüp, onları harekete geçirici bir ișlev gören yeni bir milli kimlik pathosu, bir tür milli duygu üretim mekanizması' olarak tanımlamaktadır (s.18).

Yeni Osmanlıcılık, ilk olarak, Türkiye askerinin 1974'te Kıbrıs'a yaptığ1 çıkartma sonrası adanın üçte birini kontrolü altına alması üzerine Yunanistan tarafından ortaya konulmuş bir teoridir. Yakın zamana kadar fazla dile getirilmeyen bu teori, 8. Cumhurbaşkanı Turgut Özal'la yeniden zikredilmiş, günümüzde ise eski Başbakan Ahmet Davutoğlu'nun diş politikaya ilişkin gösterdiği hamleler üzerine tekrar gündeme gelmiştir (Yenigün, 2010, s.26).Hala bir teori olmakla birlikte, milliyetçi söylemin yeni tarzı olması açısından ayrı bir önem taşımaktadır. Siyasal iktidarın ürettiği 
bir söylem olması itibariyle, mevcut seçmen kitlesi tarafından büyük ilgi görmüştür. Bu doğrultuda, hem söylemin toplumun bir kısmında yarattığ1 heyecanın, hem de eski duyulan özlemin ürünü olarak, siyasal iktidara yakınlığıyla bilinen Osmanlı Ocakları ve Yeni Osmanlılar Saltanat Derneği kurulmuştur. 2003 sonrasında yeni Osmanlı iddiaları gündeme gelse de, özellikle 2009'da Yeni Osmanlıcılık kavramı sıkça tartışılan bir konu olmuştur. Ancak siyasal iktidarın 2002' de iktidar olduğu ve onun bu zamana kadar yarattığı bir fikir olarak görülmesi yanlıştır. Çünkü bu fikir Türkiye'de üretilmemiş, dışarıda üretildikten sonra Türkiye'ye ve bölge ülkelerine servis edilmiştir. Öyleyse Türk Milliyetçiliğinin yeni yüzü olan ve art-sürekli bir söylem olarak kabul edebileceğimiz Yeni Osmanlıcılık dahi küreselleşmenin getirdiği birçok süreç gibi içerden değil dışarıdan gelen bir kavram olarak kabul edilebilir. Fakat bu kavram Claude LéviStrauss'un da belirttiği üzere (2013) mitler yardımıyla doğallaşmaktadır. Bu noktada Stuart Hall (2005), medyanın anlamın yeniden üretilmesinde rıza sağlanması açısından "herkesin anlaştığı şeyin" uzlaşma olduğunu bunun da üretildiği yerin medya olduğunu öne sürer. Kendisini 'muhafazakâr demokrat' kimliğiyle tanıtan AK Parti tarafından da benimsenmiştir. CIA'nin gölge kuruluşu olarak tanımlanan ABD merkezli düşünce kuruluşu Stratfor'un Başkanı George Friedman tarafından Mart 2009'da yayınlanan raporda, Türkiye'nin Avrupa Birliği üyeliğinden vazgeçerek 2012'den itibaren çok güçleneceği, 2023'de bölgenin tek gücü olacağ1, 2040 'da ise eski Osmanlı İmparatorluğu sinırlarında söz sahibi olarak bölge devletlerine valiler atayacağı iddia edilmektedir (Yenigün, 2010, s.27).Raporun, dünya genelindeki emperyalist politikalarıyla tanınan ABD'nin resmi istihbarat kuruluşuna yakın olan Stratfor tarafından yayınlanması ve muhafazakâr demokrat kimliğiyle birlikte milliyetçi politikalarıyla da bilinen bir siyasal iktidar tarafından benimsenmesi, en az fikrinin bir ulus devletin hem iç hem de dış politikası olarak kabul görmesi kadar çelişkilidir.

Yeni Osmanlıcılık, özellikle Türkiye'nin dış politikasında yankı bulsa da ülke sınırlarına yönelik politikaların büyük çoğunluğunda belirleyici bir rol oynamaktadır. Toplumsal belleğin geçmişten beslenerek günümüzde yeniden şekillenmesi fikrinden yola çıkarsak pek çok ritüel ve etkinlik, Yeni Osmanlıcılık-milliyetçi söylem ilişkisini destekler niteliktedir. Son dönemde hizmete giren köprülere Yavuz Sultan Selim ve Osman Gazi 
isimlerinin verilmesi, Osmanlı İmparatorluğu'nun Birinci Dünya Savaşı'ndaki Çanakkale zaferinin eskiye nazaran daha anlamlı ve daha coşkulu bir biçimde kutlanması, aynı şekilde İstanbul'un fethinin yıl dönümlerinde yapılan kutlamalar, bir milliyetçi söylem biçimi olan Yeni Osmanlıcılık'ın içeride dış politikadan daha çok uygulamaya konulduğunu göstermektedir. Ayrıca yukarıda verilen örnekler, Ankara Belediyespor'un zaman içerisinde adını Ankara Büyükşehir Belediyespor, Ankaraspor, ardından da Osmanlıspor olarak değiştirmesiyle, özellikle son dönemde Osmanlı İmparatorluğu'nu konu alan sinema filmleriyle dizi filmlerin yayınlanmasıyla ve ulusal televizyon kanallarında Osmanlı İmparatorluğu'na ilişkin çeşitli yayınların sistematik olarak sürdürülmesiyle artırılabilir. Buradaki örneklerde de görüldüğü üzere hangi ülke sınırları içerisinde olursa olsun milliyetçi söylemler birer toplumsal bellek oluşturabilmek için tekrar edilmeye mahkûmdur. Bu noktada Yeni Osmanlıcılık'ın azar azar ama sistematik tekrarı milliyetçi söylemi daha sağlam zeminde kalıcı kılmaktadır.

Dünyanın fazlasıyla küreselleştiği bir çağda hem milliyetçi söylem, hem de milliyetçi siyaset biçimi olarak Yeni Osmanlıcılık'ın değerlendirilmesi açısından iki husus ön plana çıkmaktadır. Birincisi, onun, toplum tarafından devletin dış politikasında Türk milliyetçiliğinin ve muhafazakârlığının küreselleşme biçimi olarak algılanması, toplum genelinde milli duyguları harekete geçirerek devlete ve millete olan bağlığı artırmaktadır. İkincisi, toplumdaki etnik toplulukların sindirilmesi ve asimile edilmesi açısından bir araç olarak kullanılmaktadır. Özellikle geçmişe olan özlem ve tarihteki milli zaferlerin toplumsal bellek kendisine yeniden yer bulması, hem egemen etniğin bireyleri tarafından olumlu karşılanırken, hem de diğer etkin grupların "Osmanlı hoşgörüsü" altında yeniden birlikte yaşamı inşa etme açısından umut verici olabilir. Her iki husus açısından bakıldığında Türkiye'nin küreselleşme tehdidine karşı aldığı bu önlem, Avrupa Birliği'yle olan ilişkilerin bu denli zayıfladığı bir dönemde- bireylerin devlete ve millete olan bağlığıyla toplumsal bütünlük boşluğunu gidermesi anlamında geçici ya da kalıcı bir çözüm sunmaktadır.

Hem Türkiye'deki, hem de ABD'deki birbirinden farklı milliyetçi söylemlere bakıldığında şu sonuçlara varılmıştır: Birincisi Türkiye'deki Yeni Osmanlıcılık fikri, Türk milliyetçiliğinin ve muhafazakârlığının küresel- 
leşme biçimini ifade etmektedir. Bu durum milliyetçiliğin, ulus devlet karşısında küreselleşme tehditlerine tepki olarak geliştirdiği, kendi küresel siyaset yapma biçimi olarak görülebilir. İkincisi, küresel-hâkim kültüre karşı öne sürülen Yeni Osmanlıcılık kimliği ve kültürü, toplumun ulus devlete ve milliyete bağlılı̆̆ını artırma hedefinde olup, söz konusu hâkim kültüre karşı bir direniş biçimidir. Üçüncüsü, Yeni Osmanlıcılık fikri, "Bir İdeoloji Olarak Milliyetçilik" başlı̆̆ı altında milliyetçiliğin karakteristik özelliklerini ve "Milliyetçi Söylem" başlığın altında da milliyetçi söylemin inşa ettiği milli kimliğin toplumda yaratmak istediği kültür biçimini genel olarak resmettiği için bu anlamda önemli bir örnektir. Nitekim Heywood'a göre (2013)Batılı ülkelerdeki insanlar, küresel markaların ve küresel kültürün yerine gittikçe artan biçimde Batılı olmayan markalara ve kültürlere karşı ilgi duymaktadır. Varılan tüm bu sonuçlar gösteriyor ki, milliyetçilikle küreselleşme fikirleri birbirine zıt gibi gözükse de bazı noktalarda işbirliği içinde olduğu, bazı noktalarda da milliyetçiliğin küreselleşmeye karşı bir kalkan görevini üstlendiği ortadadır. Bu anlamda her iki fikrin ya da ideolojinin birbiriyle olan ilişkisinde kesin yargılara varmanın güç olduğu söylenebilir.

'Küreselleşmenin Geleceği Lexus ve Zeytin Ağacı' kitabında Thomas Friedman (2010),küreselleşme sistemini açıklarken insanlık durumunu 'tavırlı bir turist' olarak ortaya koyar. Friedman'a göre küreselleşme sistemi duvarları yıkarken insanları 'altın deli gömleği giymiş elektronik sürüler'e dönüştürür. Bu durumun dipten gelen dalga ile ters tepki yapacağını savunan Friedman,'rasyonel bir coşkunluk'tan söz eder. Burada Friedman'ın rasyonel coşkunluğunu fitilleyen ateşini, daha önceden de olduğu gibi millete dönüş veya milliyetçilik olarak algılamak yerinde bir saptama olacaktır (Friedman, 2010). Bunun yanı sıra Friedman'a göre ileriye giden daima bir yol vardır, bu devrimdir ve devrimin adı ABD'dir. Küreselleşmenin sürdürülebilmesi için bir dünya tablosuna ihtiyaç olduğundan bahseden Friedman, buna ek olarak bütünleşmeci sosyal-güvenlikçi politikanın da gerekliliğinin altını çizer. Burada dünya tablosu için olmazsa olmazın kamuoyu olduğunu söyler ve kamuoyu yoksa hiç bir politikanın sürdürülemeyeceğinden bahseder. $\mathrm{O}$ zaman milliyetçiliğin meşrulaştığ 1 ve kamuoyunu doğrudan etkilediği yer olarak iletişim teknolojileri her zamankinden daha fazla önemli konuma gelmektedir ve gelmeye devam edecektir. Bu noktada Zygmunt Bauman (2012)artan 
mekânsal ayrımın küreselleşme süreçlerinin ayrılmaz bir parçası olduğunu belirtirken zaman ve mekânın keskin bir şekilde farklılaşmasından ötürü milliyetçiliğin yerelliklerine saplanıp kalmasını ve anlam ve yorumlamanın giderek daha fazla bağımlı hale geldiğini eleştirir. Ayrıca bir yere sabitlenmiş tüm toplumsal ve kültürel bütünlüklerin aşınması ve zayıflamasının modern bir süreç olduğunu öne süren Bauman, Ferdinand Tönnies'in modernlik formülüyle topluluk-cemaatten toplum-cemiyete geçişini tekrar anımsatır. Burada söz konusu modernlik formülü küreselleşme ve milliyetçilik tartışmaları bir arada düşünüldüğünde tersine dönen bir süreç olarak karşımıza çıkmaktadır ki, Yeni Osmanlıcılık da bu noktada cemaat algısına dönüş olarak yorumlanabilmektedir. Bununla birlikte Türkiye toplumu her türlü gündelik hayat pratikleri içerisine yerleştirilen giderek yoğunlaşan biçimlerde Osmanlı tarih anlatısını hatırlatan duygusal yatırımlarla siyasal söylemlerin öznesi durumuna geldi.

\section{Sonuç}

Milliyetçilik her ne kadar Fransız Devrimi sonrasında ortaya çıkan bir ideoloji olsa da, ona ilişkin kuramsal tartışmaları yürütenlerin genel eğilimi, milliyetçiliğin, modernleşme süreçlerinin toplumlarda yarattığı bütünlük ihtiyacını doldurduğu yönündedir. Nitekim Hobsbawm, Anderson, Smith ve Copeaux tarafından milliyetçilik, modernleşme süreçleriyle birlikte baş gösteren toplumsal bütünlük soruna karşı geliştirilen bir çözüm önerisi olarak görülürken, özelde Öz'ün temsil ettiği görüşe göre, milliyetçilik birlikteliğin garantörü konumunda olup, bu anlamda milliyetçiliğin dışında böylesi bir siyasi sorumluluk sistemini yaratacak başka bir ideoloji bulunmamaktadır. Bu noktada, küreselleşme olgusu, milliyetçiliğin günümüzdeki durumunu açıklamak ve anlamak adına bir maymuncuk rolüne bürünmüştür. Çünkü küreselleşme, her ne kadar milliyetçiliği açıklama noktasında söz konusu eylemi karmaşık bir hale büründürüyor gibi görünse de, onsuz bir milliyetçilik açıklamasını ve yorumunu ortaya koymak yanlış ve yanıltıcıdır. Peki, bu noktada Yeni Osmanlıcılık nerede son bulacaktır? Sınırı neresi olacaktır? Yoksa sınırlar ötesi bir yayılma göstererek küreselleşmenin farklı bir örneğini mi oluşturacaktır? 
"Küreselleşme Fikrine Karşı Milliyetçiliğin Tutumu" başlığı altında değinildiği üzere, küresel çağda milliyetçi politikaları kesin bir yargıyla yorumlamak ya da küreselleşme ve milliyetçilik ilişkisini formülize ederek ele almak yanlış bir yaklaşımdır. Çünkü ulus devletler, küresel-hâkim kültüre karşı mensuplarına milli kültürü dayatarak hem devlete ve millete olan bağlılığı artırmayı amaçlarken, hem de toplumdaki egemen etninin dışındaki etni gruplarını da manipüle ve asimile ederek olası etnik çatışmaların gerçekleşmesine engel olmak istemektedir. Milli kültürü ve milli kimliği küreselleşme tehdidine korumakla birlikte, diğer yandan da kendi küresel kültürünü ve küresel kimliğini yaratıp, yayılmacı bir milliyetçilik politikasını uygulamaya sokmak istiyor ki, bunu hem Türkiye'deki Yeni Osmanlıcılık hareketinde, hem de söylemlerinde görmek mümkündür. Yeni Osmanlıcılık fikri, toplumun ulus devlete ve milliyete bağlılığını artırma yönünde inşa edilmiş bir hareket olmakla birlikte hâkim kültüre karşı bir direniş biçimi olma özelliğini de taşımaktadır. 


\title{
EXTENDED ABSTRACT
}

\section{Revisiting Nationalism Under Global Age Discussions: The Construction of the New Ottoman Discourse}

\author{
Dilan Çiftçi - Fuat Boğaç Evren \\ Near East University
}

The concept of globalization, its functionality, its debates, the way it manages it, the approaches that believe that it will change the whole world needs to be revised. Despite of the popularity of concept, there are discrepancies on interpretation and understanding of it. Although it seems it is hard to define the globalization, there is also consensus with the services and interpretations of it by scholars. The rise of the nationalism and nationalistic policies in $21^{\text {st }}$ century brought about the necessity of nationalist integration of the globalization discussion in the field. Thus, the economic crisis in any country, political crisis, popular uprising, military coup, democratic initiatives and legal reform attempts to affect other countries more or less began to become commonplace. There are political, economic and cultural dimensions of globalization, which can be seen as a result of the dynamic of expansion and diffusion of the capitalist mode of production. In this study, it will be discussed with its political-cultural dimensions, effects and the relationship between globalization and nationalism which is expected to be opposed to each other will be discussed. Moreover, instead of explaining nationalist ideology with globalization or considering it as a result, it is more meaningful to consider its attitude and its resistance against the 'blinding' power of globalization to the borders of the country.

The main problematic of the study, which aims to carry out this discussion, is based on how nationalism has risen in an age when globalization has shown the effects to be so effective and profound. In addition to that, questioning the approach of nationalist ideology to events and phenomena created by globalization is one of the main subjects of this study. The concepts of nation and nationalism, which constitute the basic dynamics 
of the debate, will be approached with the concept of communication network, urbanization, capitalism, neo-liberalism and multinationalism. On the other hand, the debate approaches to the globalization with regards to discourse analysis and its critics. In this sense, first of all the critics and dimensions of globalization, then the nationalist ideology and discourse definition of nationalism will be discussed. For more than ten years, in Turkey's political jargon and social repertoire, the concept of Neo-Ottomanism as rising quickly and finds a place in the social agenda. In this fast-paced place, it is also found in the terminology of the political field in various forms, which benefited from the media effects.

While the concept imagines a grand narrative of the past, it also provides the practice of establishing new political identities through stories built by the media. These narratives form the cornerstones of knowing, understanding and making sense of the world through social and emotional investments. Because of all these reasons, every research conducted on this concept will be the object of an academic curiosity. In this study, a case study is used which is one of the common qualitative research methods used in social sciences. At this point, critique of globalization by taking more than one occasion the globalization debate in Turkey has been analyzed in a holistic approach. Multidimensional data collection tools were used in this study. Collected data interpreted in two phases. In first phase the conceptualization of the concepts were made separately, then the comparative approach has been used. Although nationalism is an ideology that emerged after the French Revolution, the general tendency of those who conduct the theoretical debates about it is that nationalism fills the need for integrity created by the processes of modernization in societies. At this point, the phenomenon of globalization has assumed the role of a master key to explain and understand the recent nationalism examples. Although globalization seems to complicate the act of explaining nationalism, it is vital to include both of them in discussion. In the global era, interpreting nationalist policies with a definite judgment or to formulating the relationship between globalization and nationalism is not inclusive. Since nation states aim to increase loyalty to the state and nation by imposing national culture on their members against the global-dominant culture, and they want to prevent possible ethnic conflicts by manipulating and assimilating ethnic groups other than the dominant ethnics in society. 
Although protect national culture and national identity from globalization threatens, on the other hand, it creates its own global culture and global identity, expansionist nationalist policy lays in the discourse of the NeoOttomanism movement in Turkey. The idea of neo-Ottomanism is a movement built to increase the loyalty of the society to the nation-state and nationality, it is also a form of resistance against the dominant culture.

\section{Kaynakça / Reference}

Althusser, L. (2010). İdeoloji ve devletin ideolojik aygıtları. (A.Tümertekin, Çev.) İstanbul: İthaki.

Barthes, R. (1990). Mythologies. New York: NoondayPress.

Bauman, Z. (2012). Küreselleşme-toplumsal sonuçları.(A. Yılmaz, Çev.) İstanbul: Ayrintı.

Beck, U. (1999). Siyasallığın icadı. (N.Ülner, Çev.) İstanbul: İletişim.

Berger, P. (2003). Küreselleşmenin kültürel dinamikleri. (P. Berger ve S. P. Huntington Der.), Bin Küre Bin Bir Küreselleşme-Çă̆daş Dünyada Kültürel Çeşitlilik. içinde (9-26). İstanbul: Kitap Yayınevi.

Bergson, H. (2015). Madde ve bellek. (I. Ergüden, Çev.) İstanbul: Dost.

Berman, M. (2013). Katı olan her şey buharlaşıyor. (Ü. Altuğ ve B. Peker, Çev.)İstanbul: İletişim.

Billig, M. (2002). Banal milliyetçilik.(C. Şişkolar, Çev.) İstanbul: Gelenek.

Brookes, R. (1999). Newspapersand national identity: The BSE/CJD Crisisandthe British press. Media, Culture\&Society, 21 (2), 247-263.

Calhoun, C. J. (1997). Nationalism. Buckingham: Open University.

Chatterjee, P. (1996). Milliyetçi düşünce ve sömürge dünyası. (S. Oğuz, Çev.) İstanbul: İletişim.

Copeaux, E. (2002). Türk milliyetçiliği: Sözcükler, tarih ve işaretler.(M. Gültekingil ve T. Bora Der.), Modern Türkiye'de Siyasi Düşünce: Milliyetçilik. içinde (44-52). İstanbul: İletişim.

Fiske, J. (1996). İletişim çalışmalarına giriş. (S.İrvan, Çev.) Ankara: Ark.

Friedman, T. (2010). Küreselleşmenin geleceği Lexus ve Zeytin Ağacı. (E. Özsayar, Çev.) İstanbul: Boyner.

Gökalp, E. (2007). Milliyetçilik: Kuramsal bir değerlendirme. Anadolu Üniversitesi Sosyal Bilimler Dergisi, 7(1), 279-298. 
Habermas, J. (2001). Avrupalı ulus devlet: Başarıları ve sınırları-Egemenlik ve vatandaşlığın geçmişi ve geleceği üzerine. (M. Armağan vd. Der.), Tartışılan Sınırlar Değişen Milliyetçilikler içinde (79-96). İstanbul: Şehir.

Habermas, J. (2012). “Öteki” olmak “öteki”yle yaşamak:Siyaset kuramı yazıları. (İ. Aka, Çev.) İstanbul: Yapı Kredi.

Hall, S. (2005). The rediscovery of 'ideology': Return of the repressed in media studies.( M.Gurevitch, vd. Der.), Culture Society and The Media içinde (56-90). London: Methuen.

Hegel, G. W. F. (2006). Tarih felsefesi. (A. Yardımlı, Çev.) İstanbul: İdea.

Hekimoğlu, H. B. (1989). Modernleşme ve siyasal istikrarsızlık. Toplum ve Bilim, 46-47, 131-142.

Held, D. (1995). Democracy and the global order: From the modern state to cosmopolitan governance. Cambridge: Polity.

Heywood, A. (2013). Siyasi ideolojiler.(A. K. Bayram, Çev.) İstanbul: Adres. Heywood, A. (2014). Siyaset. (B. B. Özipek, Çev.) İstanbul: Adres.

Hobsbawm, E. (1993). 1780'den Günümüze milletler ve milliyetçilik: Program, mit, gerçeklik. (O.Akınhay, Çev.) İstanbul: Ayrıntı.

Jessop, B. (2005). Ulusal ekonomi ve mantık(sızlık)ları üzerine düşünceler. (B. Yarar ve A. Özkazanç Der.), Hegemonya, Post-Fordizm ve Küreselleşme Ekseninde Kapitalist Devlet içinde (267-300). İstanbul: İletişim.

Karyelioğlu, S. (2008). Küreselleşen dünyada uluslarm inşa sürecinde ortaya çıkan özerklik arayışları: Aydınlık hareketinde değişen milliyetçi söylemler. Yayımlanmamış Doktora Tezi, Ege Üniversitesi, İzmir.

Keyman, F. ve Sarıbay, A. Y. (2010). Global Yerel eksende Türkiye. İstanbul: Alfa.

Lévi-Strauss, C. (2013). Mit ve anlam. (G. Y. Demir, Çev.) İstanbul: İthaki. Foucault, M. (1998). Özne ve iktidar.(K. Park, Çev.), Defter Dergisi, 34, 151167.

Oppenheimer, F. (1997). Devlet.(A. Şenel ve Y. Sabuncu, Çev.) İstanbul: Engin.

Öz, E. (2002). 21. Yüzyılda milli devlet, küreselleşme ve Türk milliyetçiliği. (M. Gültekingil ve T. Bora Der.), Modern Türkiye'de Siyasi Düşünce: Milliyetçilik.içinde (751-762). İstanbul: İletişim. 
Said, E. (2013). Şarkiyatçılık: Batı'nın şark anlayışları, (B.Ülner, Çev.) İstanbul: Metis.

Saussure, F. D. (2013). Course in general linguistics. London: Duckworth. Scholte, J. A. (2005). Globalization: A critical introduction. London: Palgrave. Smith, A. D. (1994).Milli kimlik. (B. S. Şener, Çev.) İstanbul: İletişim.

Smith, A. D. (2001). Milliyetçilik ve tarihçiler. (M. Armağan, vd. Der.), Tartışılan Sınırlar Değgişen Milliyetçilikler içinde (30-63). İstanbul: Şehir.

Smith, A. D. (2002). Küresel çă̆da milletler ve milliyetçilik. (D. Kömürcü, Çev.) İstanbul: Everest.

Şahin, K. (2007). Bir ideoloji olarak milliyetçilik. Akademik Bakış, 12, 1-9.

Şimşek, U. ve Ilgaz, S. (2007). Küreselleşme ve ulusal kimlik. Atatürk Üniversitesi Sosyal Bilimler Enstitüsü Dergisi, 9 (1), 189-199.

Tokdoğan, N. (2018). Yeni Osmanlıcılık. Ankara: İletişim Yayınları.

Traverso, E. (2009). Geçmişi kullanma kılavuzu, (I. Ergüden, Çev.) İstanbul:Versus.

Türkbağ, A. U. (2002). Pasta tarifleri üzerine bir inceleme: Küreselleşme ve adalet. Doğu Batı Düşünce Dergisi, 18, 227-236.

Volosinov, V. N. (1973). Marxismand the Philosophy of Language. (L.Matejka, Çev.) Cambridge: Harvard University.

Yenigün, C. (2010). Dış politikada "Yeni Osmanlıcıllk" kime yarar? Mostar Dergisi, 60, 26-30.

Yetim, N. (2002). Küresel üretim yapılanmasına kültürel yanıtlar: Ulusalyerel? Doğu Batı Düşünce Dergisi, 18, 129-139.

Yıldırım, E. (2015). Modernliğin eleştirisi ve 'milliyetçi söylem' bağlaminda milliyetçiliğe yeniden bakmak. Amme İdaresi Dergisi, 48(1), $1-3$.

\section{Kaynakça Bilgisi / Citation Information}

Çiftçi, D. ve Evren, F. B. (2019). Küresel çağ tartışmaları altında milliyetçiliğe yeniden bakmak: Yeni osmanlıcılık söyleminin inşası.OPUSUluslararası Toplum Araştırmaları Dergisi, 11(18), 2965-2995. DOI: 10.26466/opus.536362 